\title{
Biopelumas dari Minyak Nabati (Review)
}

\section{Biolubricant from Vegetable Oil (Review)}

\author{
Sri Wahyuni Santi.Rahardiningrum ${ }^{1 *}$, Mahreni $^{1}$., Renung Reningtyas ${ }^{1}$., Raden Hendri Gusaptono ${ }^{2}$ \\ ${ }^{1}$ Fakultas Teknik Industri, Universitas Pembangunan Nasional “Veteran” Yogyakarta, Jl SWK 104 Condongcatur, \\ Yogyakarta, 55283 \\ ${ }^{2}$ Prodi Managemen, Fakultas Ekonomi, Universitas Pembangunan Nasional “Veteran” Yogyakarta, Jl SWK 104 \\ Condongcatur, Yogyakarta, 55283
}

\section{Artikel histori :}

Diterima November 2016

Diterima dalam revisi November 2016 Diterima Desember 2016 Online Juni 2017

\begin{abstract}
ABSTRAK: Pertumbuhan otomotif di Indonesia terus mengalami peningkatan. Maka tak heran jika kebutuhan pendukungnya seperti pelumas juga mengalami peningkatan pula. Di Indonesia, kebutuhan akan pelumas atau oli mencapai angka 300 juta liter pertahunnya. Kira kira $40 \%$ pelumas akan dibuang ke lingkungan menjadi limbah non biodegradable dan bersifat sebagai limbah B3. Untuk menunjang lingkungan yang mendukung pembangunan berkelanjutan, dunia membutuhkan pelumas biodegradable atau biopelumas. Biopelumas dapat menyamai karakristik dan menggantikan fungsi pelumas berbasis petroleum. Bahan dasar biopelumas pada saat ini adalah minyak nabati melalui serangkaian modifikasi secara kimia dapat diubah menjadi senyawa mono, di atau tri ester. Ester dari minyak nabati menunjukkan sifat sifat fisika dan kimia lebih baik dibandingkan dengan pelumas petroleum. Baik sifat fluida pada temperatur rendah meliputi titik tuang, titik beku dan viskositas. Juga sifat tribologi (keausan) dan stabilitas terhadap oksidator pada temperatur tinggi. Dalam makalah ini dijelaskan mengenai perkembangan terbaru beberapa proses produksi bio pelumas ramah lingkungan berbasis ester sebagai formula generasi baru yang menunjang pembangunan berkelanjutan.
\end{abstract}

Kata Kunci: Biodegradable; Ester; minyak nabati; Pembangunan berkelanjutan

\begin{abstract}
Automotive growth in Indonesia continues to increase. Hence the need supporters like lubricants also increased as well. In Indonesia, the need for lubrication reached 300 million liters annually. Approximately $40 \%$ of the lubricant will be discharged to the environment becomes non-biodegradable waste and act as B3 waste. To support an environment that supports sustainable development, the world needs biodegradable lubricants or bio lubricants. Bio lubricants can emulate the characteristics and replace petroleum-based lubricants. Raw materials of bio lubricants at this time is a vegetable oil. Vegetable oil through a series of chemical modifications can be converted into a compound mono, di or tri Ester. Ester of vegetable oil exhibits physical and chemical properties are better than petroleum lubricants. Neither the nature of the fluid at low temperatures include pour point, freezing point and viscosity. Also the nature of Tribology (wear) and stability against oxidizing agents at high temperatures. In this paper described the latest developments some production processes based environmentally friendly bio lubricants ester as a new generation formulas that support sustainable development.
\end{abstract}

Keywords: Biodegradable; Esther; Vegetable oil; Sustainable development

\section{Pendahuluan}

Sejarah bio pelumas telah dimulai sejak tahun 1877. Pertama kali dihasilkan melalui reaksi Firiedel dan Crafts menggunakan bahan baku hidrokarbon dan katalis tri aluminium klorida. Pelumas ini disebut pelumas sintetis. Pada tahun 1937 telah diproduksi pelumas menggunakan bahan baku olefin melalui reaksi polimerisasi. Selanjutnya ribuan jenis ester telah dicoba sebagai pelumas di Jerman pada tahun 1938-1944. Baru pada tahun 1944 Zurich Aviation Congress (ZAC) tertarik memproduksi ester sebagai pelumas sintetis. AMSOIL mengembangkan pelumas $100 \%$ sintetis dan telah mendapatkan sertifkat dari API pada tahun 1972. Pada tahun 1975 MOBIL OIL telah mengkomersilkan pelumas tersebut. Perusahaan lain yang telah mengembangkan pelumas sintetis adalah Petroleum giants Mobil, Quaker State, Castrol, Valvoline

*Corresponding Author:

Email: mahreni@upnyk.ac.id 
dan Pennzoil. Pelumas sintetik terus berkembang karena ramah lingkungan dan sampai tahun 2012 telah ada 60 merek pelumas sintetis yang telah digunakan di berbagai industri penerbangan, militer dan sebagian besar komponen pelumas sintetis adalah ester. Meliputi ester phosphate, polialkilena glikol, ester dari minyak nabati, polialfaolefin (PAO), aromatik teralkilasi, dan polibutena diramalkan akan mendominasi pasar. (Vander Waal et al, 1993 dalam Nagerdramma \& Savita, 2012). Pelumas sintettis adalah senyawa Ester relatif lebih mudah diurai oleh mikroorganisme dibandingkan dengan pelumas dari fraksi minyak bumi. Pelumas sintetis berkembang karena didorong oleh kesadaram masyarakay untuk menciptakan pembangunan berkelanjutan.

\subsection{Latar belakang bio pelumas}

Pada saat ini polusi dan lingkungan selalu dihubungkan dengan aspek kesehatan dan menjadi isu publik yang penting untuk dicarikan solusinya. Polusi lingkungan yang disebabkan oleh pelumas adalah limbah pelumas merupakan limbah B3 dan non biodegradable. Sehingga akumulasi limbah pelumas akan berakibat pencemaran tanah, air dan udara. Untuk mengatasi permasalahan ini, maka harus ada usaha untuk menggantikan pelumas non biodegradable yaitu pelumas bio. Tanah dan air dicemari oleh pelumas bekas yang dibuang langsung ke lingkungan, Bahan volatil yang ada di dalam pelumas akan terekspos ke udara mencemari udara. Pelumas yang dibuang ke sungai akan terakumulasi di badan air mencemari perairan. Lama lama akan terjadi penetrasi ke sumur dan area pertanian. Pencemaran lingkungan membawa dunia kepada suatu kondisi yang tidak nyaman untuk kehidupan.

Suatu keinginan masyarakat kini ingin mengembalikan alam kepada kondisi yang nyaman untuk hidup ini menjadi gaya dorong untuk mengembangkan teknologi yang berkaitan dengan produksi pelumas ramah lingkungan yaitu pelumas yang bersifat biodegradasi. Sampai saat ini pelumas dari petroleum masih mendominasi pemakaian pelumas di dunia. Tetapi dalam perkembangannya kini telah dikenal dua jenis pelumas lain yaotu pelumas hasil modifikasi kimia hidrokarbon dan yang kedua adalah Ester minyak nabati (Mubarak et al 2014).

\subsection{Ester sintetik}

Senyawa Ester telah digunakan sebagai pelumas sudah lebih dari 50 tahun yang lalau sebagai pelumas pada mesin jet. Hal ini disebabbkan karena Ester mempunyai sifat yang unik yaitu memiliki sifat yang baik pada temperatur rendah. Terutama Pour point rendah sehingga pelumas akan dengan mudah mengalir walaupun digunakan pada lingkungan yang suhunya rendah. Titik didih tinggi sehingga fraksi pelumas yang menguap relatif kecil dan polusi yang disebabkan oleh uap pelumas rendah. Suatu hambatan komersialisasi ester sebagai pelumas adalah harganya lebih mahal. Selain Ester dikenal senyawa Poli-ol dari senyawa Ester mempunyai kelebihan menunjukan sifat stabilitas termal yang tinggi, Pour point rendah dan Indek viskositas tinggi. Mempunyai sifat anti aus yang tinggi sehingga pelumas Poli-ol Ester dapat digunakan untuk jenis mesin yang bervariasi. Dalam pemakaian pelumas Ester dapat dicampur dengan pelumas minyak mineral (Ebtisam et al, 2017).

\subsection{Status bio pelumas saat ini.}

Kebutuhan pelumas sedunia mencapai 35 juta $-5,3$ juta ton/tahun semenjak 1991. Jerman adalah negara yang menggunakan pelumas terbesar kira kira $47 \%$ dari total konsumen di dunia (2,5 juta ton/tahun). Konsumsi untuk industri mencapai 1,7 juta ton/tahin (32\%). Penerbangan dan transportasi laut (0,5 juta ton/tahun) atau 9,4\% dan pelumas untuk proses 0,6 juta ton/tahun $(11,3 \%)$. Negara atau perusahaan produsen pelumas Diantaranya adalah Jepang, Malaysia, Spanyol, Taiwan, India, German, Rusia, China). (Ponnekanti Nagendramma \& Savita Kaul, 2012). Indonesia kini telah memiliki pabrik pelumas diantaranya memproduksi bio pelumas "Meditran SX Bio", menggunakan bahan baku minyak sawit dan bio diesel.

\section{Kajian Literatur}

Minyak nabati atau lemak tidak dapat langsung digunakan sebagai pelumas. Hal ini disebabkan karena minyak nabati belum memenuhi standar pelumas. Minyak nabati tidak stabil terhadap reaksi oksidasi. Hal ini disebabkan karena adanya ikatan rangkap pada asam karboksilat yang terikat pada minyak. Ikatan rangkap mudah terbuka apabila ada oksidator yang ada di lingkungan ketika pelumas digunakan pada sebuah mesin. Semakin banyak ikatan rangkat semakin mudah teroksidasi. Hasil reaksi oksidasi adalah senyawa yang tidak dapat diprediksi kemungkinan adalah molekul molekul kecil yang mudah menguap. Akibat reaksi oksidasi sangat beragam diantaranya yang pasti adalah merubah struktur kimia pelumas. Molekul molekul kecil yang dihasilkan dari reaksi oksidasi adalah molekul yang mempunyai titik didih rendah sehingga mudah menguap. Efek molekul kecil adalahmeningkatnya polusi udara yang disebabkan oleh uap hasil oksidasi. Untuk menaikkan stabilitas minyak, ikatan rangkap harus dieleminasi dengan cara membuka ikatan rangkap menjadi ikatan tunggal (jenuh).

Ada beberapa tahapan untuk memodifikasi Minyak Nabati menjadi senyawa Ester. Tahap pertama adalah reaksi Hidrolisis Trigliserida menjadi Asam lemak bebas (FFA) dan Gliserol. Reaksi ini berlangsung pada temperatur $120{ }^{\circ} \mathrm{C}$, tekanan 1 atm menggunakan bantuan katalisator asam selama 1-3 jam. Gliserol adalah hasil samping sedangkan Asam lemak bebas akan direaksikan lebih lanjut menjadi senyawa turunannya yaitu senyawa Epoksi. Senyawa Epoksi adalah senyawa yang jenuh. 
<smiles>[R]C(=O)OCC(COC([R])=O)OC([R])=O</smiles><smiles>OCC(O)(O)CO</smiles>

$\mathrm{R}_{1} \mathrm{COOH}$ $\mathrm{R}_{2} \mathrm{COOH}$ $\mathrm{R}_{3} \mathrm{COOH}$ trigliserida gliserol

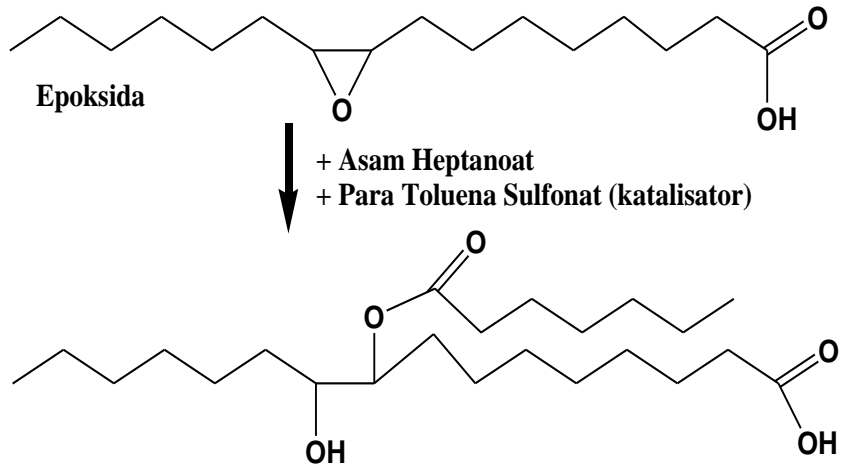

Ikatan rangkap pada Asam lemak bebas dibuka melalui reaksi pembukaan rantai menjadi rantai tertutup. Reaksi Eposkidasi ditampilkan pada Gambar 2 (Jumat Salimon et al, 2012).

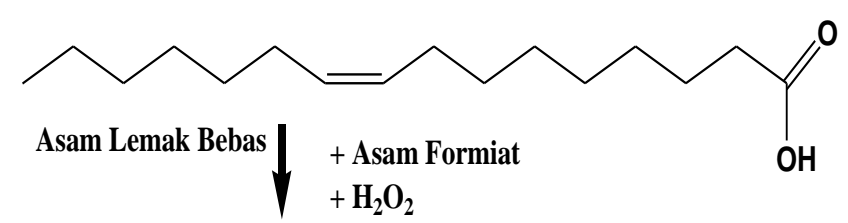<smiles>CCCCCCC1OC1CCCCCCCC(=O)O</smiles>

Gambar 2. Reaksi pembukaan ilatan rangkap pada Asam Lemak bebas menghasilkan senyawa Epoksida.(Jumat Salimon et al, 2012)

Senyawa Epoksida tidak mengandung ikatan rangkap sehingga memiliki stabilitas termal yang lebih tinggi dibandingkan dengan Asam lemak bebas. Untuk menstabilkan minyak nabati dari reaksi oksidasi, adalah dengan cara memodifikasi minyak atau trigliserida menjadi senyawa Epoksi melalui reaksi epoksidasi. Reaksi Epoksidasi adalah reaksi pembuakaan ikatan rangkap menjadi ikatan tertutup. Pada ujung senyawa masih mengikat gugus asam $\mathrm{COOH}$ maka senyawa epoksida (Gambar 2) belum dapat memenuhu persyaratan sebagai pelumas. Sifat asam senyawa menyebabkan korosi pada alat. Untuk menurunkan keasamaan, Epoksi harus dimodifikasi lebih lanjut menjadi senyawa Ester melalui reaksi Esterifikasi.

\begin{abstract}
Mono Ester
Gambar 3. Reaksi Esterifikasi Epoksida dan Asam Heptanoat menjadi Mono Ester (Jumat Salimon et al, 2012)
\end{abstract}

Hasil reaksi Esterifikasi adalah senyawa Ester yang diharapkan mempunyai stabilitas yang lebih tinggi dibandingkan dengan senyawa Epoksi karena satu gugus fungsi reaktif telah menjadi ikatan $\mathrm{C}=\mathrm{O}-\mathrm{R}$ (Ester). Tetapi masih belum memenuhi standar yang diperlukan pelumas. Stabilitas masih harus ditingkatkan lagi dengan reaksi tahap selanjutnya adalah reaksi pembentukan di dan tri Ester.

Perbaikan sifat biopelumas terus dilanjutkan dengan mereaksikan gugus fungsional yang mudah bereaksi dengan oksidator menjadi senyawa Ester. Pada Senyawa mono Ester seperti yang dapat dilihat pada Gambar 3 masih mengandung dus gugus fungsi reaktif yaitu gugus hidroksil $(\mathrm{OH})$ dan gugus karboksilat $(\mathrm{COOH})$ pada ujung rantai utama Ester. Deaktifasi kedua gugus tersebut dilakukan melalui reaksi Esterifikasi yang kedua dan ketiga. Reaksi pembentukan Di-ester dapat dilihat pada Gambar 4. Yaitu reaksi gugus $\mathrm{COOH}$ dengan Ethyl heksanol menghasilkan Di-ester.

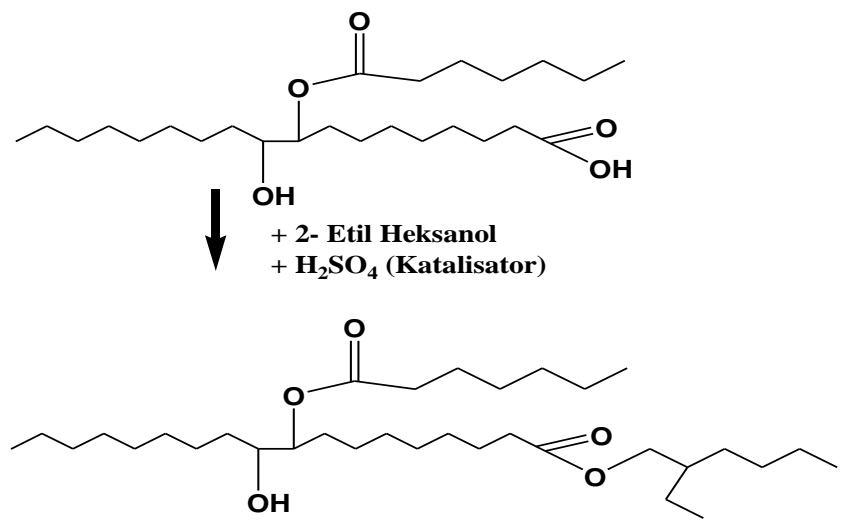

Gambar 4. Reaksi pembentukan Di- Ester dari MonoEster dan 2-Etil -Heksanol dan Asam sulfat sebagai katalisator (Jumat Salimon et al, 2012)

Di ester adalah senyawa yang mempunyai stabilitas lebih tinggi dibandingkan dengan senyawa Mono- ester. 
Tetapi sesuai dengan data yang dihasilkan dari eksperiman yang telah dilakukan oleh Jumat Salimon et al, 2012, senyawa Di- Ester dari Minyak nabati ini belum memenuhi sayarat sebagai pelumas, karena masih ada satu gugus reakstif yaitu gugus $\mathrm{OH}$ (hidroksil). Gugus hidroksil bersifat basa memerlukan Asam untuk membentuk Ester. Reaksi Di-ester dengan Asam karboksilat untuk membentuk Tri-Ester dilakukan menggunakan bantuan katalis Asam sulfat. Reaksi pembentukan Tri-Ester dapat dilihat pada Gambar 5 (Jumat Salimon et al, 2012).
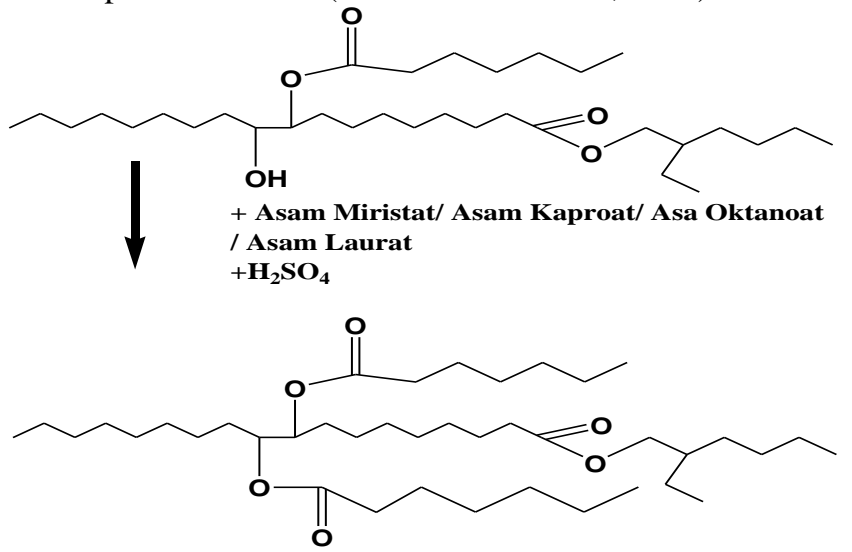

Gambar 5. Reaksi pembentukan Tri-Ester dari Di-ester minyak nabati (Jumat Salimon et al, 2012)

Selain modifikasi yang telah dilakukan oleh Salimon, modifikasi yang lebih sederhan telah dilakukan oleh (Jinho et al 2012). Trigliserida atau minyak nabati dipecah menjadi gliserol dan asam lemak bebas melalui reaksi hidrolisis. Gliserol adalah hasil samping. Asam lemak bebas ini selanjutnya direaksikan dengan alkohol menjadi mono ester (ME). Ester ini sering disebut biodisel. Dalam laporannya Jinho menguji biodisel ini sebagai biopelumas. Mono ester juga dapat dihasilkan tanpa melalui hidrolisis. Mono ester dibentuk melalui reaksi satu step yaitu reaksi transesterifikasi minyak nabati dan alkohol dengan katalis basa menghasilkan FAME (Fatty acid mono ester). Mekanisme reaksi modifikasi minyak nabati menjadi ME dapat dilihat pada Gambar 6.

Proses modifikasi minyak nabati menjadi biopelumas telah banyak diteliti, diantaranya adalah berbahan minyak jarak. Minyak jarak adalah minyak yang tidak bisa dikonsumsi sebagai pangan sehingga minyak jarak sebagai bahan baku biopelumas tidak menggangi ketersediaan pangan. Proses pembuatan biopelumas dari minyak jarak pertama-tama merubah minyak menjadi metil ester (JME). Selanjutnya 150 gram Metil ester dari minyak jarak dimasukkan ke dalam labu (reaktor) ditambah dengan Trimethylolpropane (TMP) dengan perbandingan mol tertentu. Karena reaksinya adalah bolak balik untuk memperbesar konversi mol metil ester dibuat ekses. Perbandingan mol JME (Metil ester minyak jarak) : mol TMP $=3,9: 1$. Katalis adalah sodium methoxide $\left(\mathrm{NaOCH}_{3}\right)$ dalam $30 \%$ methanol. Katalis yang digunakan adalah $1 \%$ dari berat total reaktan. Untuk menggeser reaksi kekanan, metanol sebagai hasil reaksi dipisahkan dari campuran reaksi dengan cara di vakum. Tekanan vakum dipertahankan 10 mBar. Temperatur divariasi $120{ }^{\circ} \mathrm{C}$ to $200^{\circ} \mathrm{C}$. Waktu reaksi selama 3 jam. Hasil reaksi disaring untuk memisahkan pengotor. Sampel selanjutnya dianalisis untuk menentukan pour point, Indek viskositas, flash point, spesifik grafitu, temperatur degradasi dan stabilitas oksidasi.

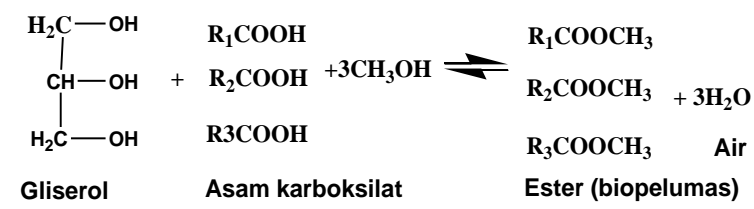

1) Hidrolisis

Jalur hidrolisis dan esterifikasi

$+\mathrm{H}_{2} \mathrm{O}$ Air

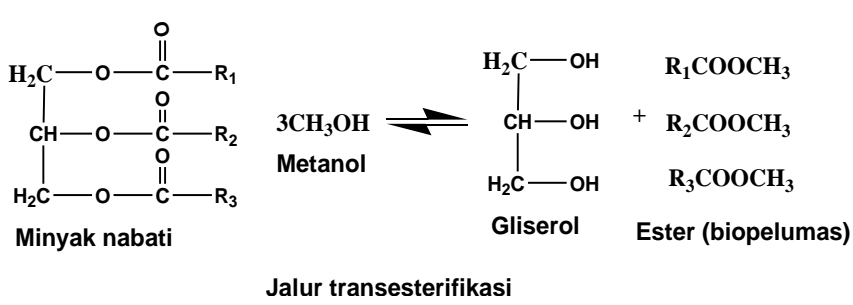

Gambar 6. Mekanisme reaksi pembentukan Biopelumas dari Minyak Nabati (Trigliserida) (Jinho et al, 2011).

Reaksi esterifikasi antara JME dan TMP dapat dilihat pada Gambar 7.(Mohammad et al, 2012)

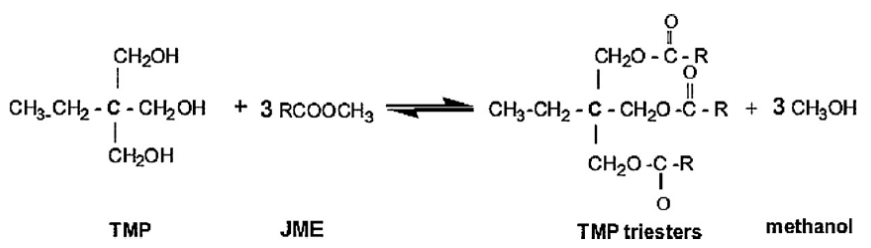

Gambar 7. Reaksi Transesterifikasi JME dan TMP (Mohammad et al, 2012)

\section{Hasil dan Pembahasan}

Perubahan sifat-sifat Minyak nabati dan Ester telah dilaoprkan oleh (Mohammad et al, 2012). Dan ditampilkam pada Tabel 2.

Dari tabel tersebut dapat dilhat bahwa indek viskositas biopelumas hasil reaksi Jathropa Methyl Ester (JME) dengan Tri Methylol Propana (TMO) lebih rendah dibandingkan dengan JME. Triester mempunyai indeks viskosotas (IV) paling tinggi pada kondisi temperatur reaksi $150^{\circ} \mathrm{C}$ yaitu 183 . Sedangkan IV minyak jatropa adalah 186. Pour point Triester turun menjadi $-6^{\circ} \mathrm{C}$ dan temperatur degradasi naik $325^{\circ} \mathrm{C}$. Indek Viskositas yang semakin rendah menunjukkan bahwa perubahan viskositas 
relatif besar nilainya apabila temperatur berubah. Seharusnya viskositas pelumas nilainya tidak banyak dipengaruhi oleh temperatur. Dari tabel diatas dapat dilihat bahwa IV pelumas dari ester minyak kedelai dan minyak Rapeseed labih tinggi dibandingkan dengan ester dari minyak sawit dan minyak jarak mentah (Mohammad et al, 2012).

Hasil penelitian yang telah dilakukan oleh (Jumat Salimon et al, 2012) dapat disimpulan bahwa Ester lebih stabil dibandingkan Trigliserida. Sifat kimia Ester ditentukan oleh keseimbangan antara panjang rantai alkil dan gugus fungsional yang terikat oleh Ester. Panjang rantai alkil Trigliserida menentukan viskositas (kekentalan) pelumas. Panjang rantai alkil juga berpengaruh terhadap Indek viskositas (IV). Semakin panjang rantai Alkil Trigliserida, viskositas dan Indek Viskositas semakin tinggi. Sedangkan titik tuang, tingkat biodgradabilitas, dan stabilitas oksidasi ditentukan oleh jenis rantai cabang. Jumlah Ester (mono, di atau tri) Ester berpengaruh terhadap kompatibiliti pelumas dan jumlah asam dari Ester ialah hambatan sterik berpengaruh terhadap stabilitas terhadap reaksi hidrolisis dan stabilitas termal. Adanya gugus ester artinya adanya sifat polar pelumas berpengaruh terhadap penguapan, sifat lubrikasi dan sifat melarutkan. Sehingga apabila dibandingkan dengan minyak mineral, Ester mempunyai kelebihan diantaranya IV tinggi (diatas 160 $\left.{ }^{\circ} \mathrm{C}\right)$, Pour point rendah $\left(-30^{\circ} \mathrm{C}\right)$, Volatilitas rendah atau tidak mudah menguap, stabilitas termal tinggi, Flash point tinggi $>260^{\circ} \mathrm{C}$, mempunyai sifat anti friksi tinggi dan mudah terbiodegradasi. Beberapa jenis ester (mono, di dan poli dan ester komplek) telah diterima sebagai pelumas.

Tabel 2. Karakristik biopelumas triester Tri Metilol Propana (TMP).

\begin{tabular}{|c|c|c|c|c|c|c|c|c|c|}
\hline Karakteristik & & Esterif & asi min & x jarak & & Minyak & Ester & Ester & Ester \\
\hline $\begin{array}{c}\text { Temperatur } \\
\left({ }^{\circ} \mathrm{C}\right)\end{array}$ & 120 & 130 & 140 & 150 & 160 & & & & \\
\hline $\begin{array}{l}\text { Viskositas } \\
(\mathrm{cSt}) 40^{\circ} \mathrm{C}\end{array}$ & 43,68 & 42,48 & 43,55 & 42,57 & 43,9 & 51,57 & 52,4 & 56,8 & 35,34 \\
\hline $\begin{array}{l}\text { Viskositas } \\
\text { (cSt) } 100^{\circ} \mathrm{C}\end{array}$ & 8,67 & 9,67 & 8,77 & 9,37 & 8,71 & 10,75 & 10,20 & 10,90 & 7,99 \\
\hline $\begin{array}{l}\text { Indek } \\
\text { viskositas } \\
\text { (IV) }\end{array}$ & 178 & 182 & 178 & 183 & 180 & 186 & 186 & 190 & 209,2 \\
\hline $\begin{array}{l}\text { Pour point } \\
\quad\left({ }^{\circ} \mathrm{C}\right)\end{array}$ & -6 & -6 & -6 & -6 & -6 & 8 & -5 & -6 & $-15,5$ \\
\hline $\begin{array}{l}\text { Temperatur } \\
\text { terurai }\left({ }^{\circ} \mathrm{C}\right)\end{array}$ & - & - & - & 325 & - & 205 & 385 & 400 & - \\
\hline Kausan (mm) & - & - & - & 0,33 & - & 0,36 & 0,24 & - & - \\
\hline
\end{tabular}

Selain Ester yang dijelaskan diatas ada lagi jenis biopelumas yang senyawanya adalah Ester polyols, diols, triols dan tetrols. Sampai saat ini telah dikenal lima jenis pelumas sintetis yang biodegradable yaitu: (1). Minyak nabati dengan kandungan asam oleat tinggi, (2). Polialpha olefin (PAOs), (3) polialkilena gliko; (PAGs), ester dibasa (Des) dan ester poliol (Pes) (Ponnekanti Nagendramma \& Savita Kaul, 2012).

Dari uraian di atas dapat disimpulkan bahwa struktur kimia suatu Bio pelumas sangat berpengaruh terhadap sifat fisika dan kimia serta sifat tribologi dari pelumas. Semakin panjang rantai yang disubstitusikan ke dalam bagian tengah rantai suatu ester akan berdampak positif terhadap pour point, cloud point dan frezzing point. Apabila rantai utama ester diperpanjang maka akan menambah hambatan sterik sehingga menghambat pembentukan kristal dan akibatnya akan menurunkan pour point dan akan menaikan anti wear berlawanan dengan onset temperatur. Hasil penelitian membuktikan bahwa ikatan rangkap pada asam lemak bebas yang terikat pada trigliserida menyebabkan trigliserida mudah teroksidasi (Nadia et al, 2011) dan (Jumat Salimon et al, 2012).

\section{Kesimpulan}

Biopelumas dari bahan baku minyak nabati seperti minyak sawit, minyak Rapeseed dan minyak Jarak dengan modifikasi secara kimia dapat memenuhi standar parameter pelumas komersial. Pour point dan indek viskositas, stabilitas oksidasi, temperatur degradasi termal, cloud point merupakan parameter yang banyak dipengaruhi oleh perubahan struktur kimia minyak nabati. Modifikasi secara esterifikasi minyak nabati menjadi ester menaikkan kekentalan (viskositas) dan Flash point. Sementara indek viskositas menurun pada biopelumas dari bahan baku minyak Rapeseed. Hasil modifikasi minyak jarak menaikkan indek viskositas dan pour point. Modifikasi minyak sawit menaikkan viskositas dan indek viskositas sementara pour point dapat dikatakan tetap. Dari laporan penelitian yang telah dilakukan dapat disimpulkan bahwa karakteristik biopelumas dari bahan dasar minyak nabati telah sesuai dengan standard pelumas komersial sehingga 
biopelumas mempunyai potensi yang besar dapat menggantikan pelumas dari bahan baku petroleum.

\section{Daftar Pustaka}

Arumugam., S, Sriram., G, R. Ellappan, 2014, Biolubricant-biodiesel combination of rapeseed oil: An experimental investigation on engine oil tribology, performance, and emissions of variable compression engine (2), Journal of Energy, Vol. 72: pp. 618-627.

Ebtisam., K, Heikal, Elmelawy., M.S, Salah A. Khalil, N.M. Elbasuny, 2017, Manufacturing of environment friendly biolubricants from vegetable oils. Egyptian Journal of Petroleum, 26, 53-59

Fessenden., R.J, Fessende., J.S. Alih bahasa Aloysius Hadyana Pudja Atmadja, 2006, Kimia Organik. Erlangga- Jakarta.

Jinho Oha, Sungeun Yanga, Chanyeon Kim, Inchang Choi, Jae Hyun Kim, Hyunjoo Lee, 2013, Synthesis of biolubricants using sulfated zirconia catalysts, Applied Catalysis A: General. Vol. 455: pp.164-171.

Jumat Salimona, Nadia Saliha, Emad Yousif, 2012, Triester derivatives of oleic acid: The effect of chemical structure on low temperature, thermo-oxidation and tribological properties, Industrial Crops and Products, Vol. 38: pp. 107-114.

Mobarak., H.M, Niza Mohamad.,E, Masjuki., H.H, Kalam., M.A, AlMahmud., K.A.H, Habibullah.,M, A.M. Ashraful, 2014, The prospects of biolubricants as alternatives in automotive applications. Renewable and Sustainable Energy. Reviews. Vol. 33: pp. 4-43.

Mohamad Faiz Mukhtar Gunam Resul, 2012, Tinia Idaty Mohd. Ghazi, Azni Idris. Kinetic study of jatropha biolubricant from transesterification of jatropha curcas oil with trimethylolpropane: Effects of temperature. Journal of Industrial Crops and Products, Vol. 38: pp. 87-92.

Nadia Saliha, Jumat Salimona, Emad Yousif, 2011, The physicochemical and tribological properties of oleic acid based triester biolubricants, Industrial Crops and Products, Vol. 34: pp. 1089-1096.

Ponnekanti Nagendramma, Savita Kaul, 2012, Development of ecofriendly/biodegradable lubricants: An overview Renewable and Sustainable Energy Reviews, Vol. 16: pp. 764-774.

Syaima., M.T.Sb, K.H. Ong, Ishenny Mohd Noor, Zamratul., M.I.M, Brahim., S.A, Hafizul M.M., 2015, The synthesis of bio-lubricant based oil by hydrolysis and non-catalytic of palm oil mill effluent (POME) using lipase. Journal homepage: www.elsevier.com/locate/rser. Renewable and Sustainable Energy Reviews. Vol. 44: pp.669-675.

Vander Waal G, Kenbeek D, 1993, Testing application and future development of environmentally friendly ester base fluids, Journal of Synthetic Lubrication, Vol. 10 (1): pp. 67-83. 